Review

\title{
Cyberbullying, Race/Ethnicity and Mental Health Outcomes: A Review of the Literature
}

\author{
Lynne Edwards ${ }^{1, *}$, April Edwards Kontostathis ${ }^{2}$ and Christina Fisher ${ }^{3}$ \\ ${ }^{1}$ Department of Media and Communication Studies, Ursinus College, PA 19426, Collegeville, USA; \\ E-Mail: ledwards@ursinus.edu \\ ${ }^{2}$ Department of Math and Computer Science, Ursinus College, PA 19426, Collegeville, USA; \\ E-Mail: akontostathis@ursinus.edu \\ ${ }^{3}$ Department of Psychology, Ursinus College, PA 19426, Collegeville, USA; E-Mail: chfisher@ursinus.edu \\ * Corresponding author
}

Submitted: 10 December 2015 | Accepted: 12 April 2016 | Published: 16 June 2016

\begin{abstract}
Cyberbullying is a relatively new phenomenon associated with the widespread adoption of various digital communication technologies, including the internet and mobile phones. As of 2013 , nearly $20 \%$ of youths in grades $9-12$ in the US reported being traditionally bullied in face-to-face encounters while almost 15\% reported being cyberbullied (Kann et al., 2014). Bullying victimization is associated with a variety of behavioral and psychological effects, from becoming bullies themselves (i.e., bully-victims), to poor academic performance, depression and suicidal ideation (Nansel et al., 2001; Wang, Nansel, \& lannotti, 2011; Willard, 2007). Research on these phenomena has focused primarily on white youth, leaving a void in our understanding of how cyberbullying has affected youth of color. This narrative literature review addresses this oversight by providing an overview of recent cyberbullying research that focuses on Hispanic, Asian and black adolescents $(k=15)$. We found that youth of color appear to be less likely to experience cyberbullying than white youth but they experience suicidal ideation and attempts at about the same rates when they do experience cyberbullying.
\end{abstract}

\section{Keywords}

bullying; cyberbullying, mental health; race; youth

\section{Issue}

This review is part of the issue "Adolescents in the Digital Age: Effects on Health and Development", edited by Dan Romer (University of Pennsylvania, USA).

(C) 2016 by the authors; licensee Cogitatio (Lisbon, Portugal). This article is licensed under a Creative Commons Attribution 4.0 International License (CC BY).

\section{Introduction}

Cyberbullying is a relatively new phenomenon, a concept with roots in traditional, face-to-face bullying and no indication of disappearing any time soon (Davison \& Stein, 2014; Olweus, 1993). As of 2013, nearly $20 \%$ of youths in grades 9-12 in the US reported being traditionally bullied and almost $15 \%$ reported being cyberbullied; recent reports estimate these numbers to be slightly higher (Kann et al., 2014). As a result of bullying victimization, many of these teens exhibit a variety of behavioral and psychological effects, from becoming bullies themselves (i.e., bully-victims), to poor academic performance, depression and suicidal ideation (Nansel et al., 2001; Wang, Nansel, \& lannotti, 2011; Willard, 2007). But these data and the research behind it don't tell us whether youth of color experience cyberbullying and its mental health effects the same way as their white peers (Hamm et al., 2015; Kowalski, Giumetti, Schroeder, \& Lattanner, 2014; Selkie, Fales, \& Moreno, 2015). This current study addresses this oversight by providing a narrative review of recent cyberbullying research that focuses on Hispanic, Asian and African American adolescents. 


\section{Cyberbullying Research}

Cyberbullying is the use of email, cell phones, text messages, and Internet sites by an individual or group of individuals to repeatedly threaten, harass, embarrass, or socially exclude someone of less power (Li, 2007; Olweus, 1993; Raskauskas \& Stoltz, 2007; SampasaKanyinga, Roumeliotis, \& Xu, 2014; Wang, lannotti, \& Nansel, 2009). Cyberbullying is similar to traditional bullying in several ways. First, both share a power imbalance between bullies and victims or bully-victims (bullies who have also been victimized) and second, both cyberbullying and traditional interpersonal bullying acts have the potential to destroy victims' relationships with others (Li, 2007; Olweus, 1993; Raskauskas \& Stoltz, 2007).

Willard's (2007) typology of cyberbullying acts demonstrates their similarity to traditional bullying while also reflecting both the escalating intensity of cyberbullying and the narrowing of the relational distance between bullies and victims. Flaming is a heated, short-lived argument that occurs between two or more protagonists who may or may not know each other. Similarly, harassment (the repeated, ongoing sending of offensive messages to an individual target) can occur between strangers or friends. However, intimate knowledge is required for impersonation or outing. Impersonation occurs when the cyberbully gains the ability to impersonate the victim and potentially interfere with his or her friendships. Bullies with access to the victim's personal communications can share intimate secrets that are potentially embarrassing (Willard, 2007, pp. 5-11). These increasingly personal violations are frequently made possible by teens' habit of sharing their passwords with friends (Lenhart, Smith, Anderson, Duggan, \& Perrin, 2015). However, the defining characteristic of cyberbullying is the use of digital technology, which allows cyberbullies to attack their victims in front of a much larger, often virtual audience for extended periods of time behind a veil of anonymity (Dempsey, Sulkowski, Nichols, \& Storch, 2009; Holfeld \& Leadbeater, 2015; Menesini et al., 2012; Raskauskas \& Stoltz, 2007; Schneider, O’Donnell, Stueve, \& Coulter, 2012). For these reasons, perpetrators may feel reduced responsibility and accountability when online compared with face-to-face situations (Horowitz \& Bollinger, 2014; Kowalski et al., 2014; Schneider et al., 2012).

Given its pervasiveness, researchers have explored bullying and cyberbullying from a variety of indicators and effects. Most traditional bullying occurs on school grounds and for girls, is frequently interpersonal (Maher, 2008; Willard, 2007). Lower income and family resources, and previous bullying experiences are predictors of bullying behaviors (Williams \& Peguero, 2013; Shojaei, Wazana, Pitrou, Gilbert, \& Kovess, 2009). However, other research has found that school bullying and cyberbullying overlapped very little (Barboza, 2015; Holfeld \& Leadbeater, 2015; Li, 2007; Kubiszewski, Fontaine, Potard, \& Auxoult, 2015; Raskauskas \& Stoltz, 2007; Schneider et al., 2012).

Youth who are socially isolated and rejected by peers may also be more likely targets for being bullied (Campfield, 2006; Hodges \& Perry, 1999; Nansel et al., 2001; Olweus, 1993; Wolak, Mitchell \& Finkelhor, 2007). Victimized children may be weaker or less psychologically confident than their peers (Hinduja \& Patchin, 2010; Hodges \& Perry, 1999; Nansel et al., 2001; Olweus, 1993; Smith \& Monks, 2008). Typical victims are more anxious and insecure; they also suffer from low self-esteem (Kubiszewski et al., 2015; Storch, Masia-Warner, Crisp, \& Klein, 2005).

Several studies have found gender differences between males and females with respect to involvement in bullying. Boys are more likely than girls to be cyberbullies and traditional bullies, whereas girls are more likely to be victims (Dempsey et al., 2009; Juvonen, Graham, \& Schuster, 2003; Klomek, Marracco, Kleinman, Schonfeld, \& Gould, 2007; Wang et al., 2009). When girls bully, they are more involved in indirect bullying (e.g., spreading rumors) compared to boys, who are more involved in direct, face-to-face and physical bullying (Dempsey et al., 2009; Nansel et al., 2001; Olweus, 1993; Wang et al., 2009).

\subsection{Mental Health Effects}

One of the biggest concerns about cyberbullying, however, is the effects on victims' mental health outcomes, particularly suicide and depression. Bullying victims, bullies, and bully-victims are at risk of a number of mental health, social, and interpersonal problems (Bhatta et al., 2014; Juvonen et al., 2003; Kubiszewski et al., 2015; Nansel et al., 2001; Price, Chin, HigaMcMillan, Kim, \& Frueh, 2013). More than half of youth who qualified as traditional bullies and cyberbullies had clinically significant anxiety scores and clinically significant depression (Price et al., 2013). Youths who are bullied are more likely to report depression, low self-esteem, poor school performance, and suicide attempts; being bullied is also associated with higher odds of suicidal ideation, regardless of an adolescent's gender, race/ethnicity, or sexual orientation (Bhatta, Shakya, \& Jefferis, 2014; Mueller, James, Abrutyn, \& Levin, 2015; Sampasa-Kayinga et al., 2014).

Gender differences persist in mental health effects, too. Girls reported with greater frequency that they felt their reputation was affected by the cyberbullying they experienced, that their concentration was affected, that it influenced their ability to make friends, and that it induced suicidal thoughts (Cassidy, Faucher, \& Jackson, 2013). Traditional bullies are more likely to be male and report lower levels of depression compared to girls; however, bullies are also more at risk for sui- 
cidal ideation than non-bullies and non-victims (Klomek et al, 2007).

As noted earlier, findings are often contradictory. For example, several studies report that bullies have the best self-concepts and the most global self-worth, while other research shows bullies are at a significantly higher risk for serious suicidal ideation and suicide attempts compared with youth who were never bullies (Houbre, Tarquinio, Thuillier, \& Hergott, 2006; Juvonen et al, 2003; Klomek et al., 2007). Bully-victims experience a great amount of psychological issues as well, including the risk of developing multiple psychopathologies, being socially ostracized by their peers, and experiencing elevated levels of depression and loneliness (Juvonen et al., 2003; Nansel et al., 2001; Shojaei et al., 2009). However, other research found that cyber victimization was only weakly associated with symptoms of social anxiety, not depression (Dempsey et al., 2009).

There have been several reviews of this literature, however, very little research has explored the role of race/ethnicity in cyberbullying. In the only literature review (thus far) to explore the role of race in bullying, Albdour and Krouse (2014) reviewed research that focused specifically on African American youth and traditional (non-cyber) bullying. In the 23 studies they reviewed, authors reported consistent findings that black teens are more involved in bullying events than their non-black peers; however, the nature of their involvement as bully, victim or bully/victim was not always clearly reported. Environmental factors like poverty and family support or abuse were significant factors in bullying involvement.

Aside from the Albdour and Krouse review, however, reviews of bullying and cyberbullying research are problematic in that they tend to exclude research that focuses on youth of color (Selkie et al., 2015), struggle to find studies about youth of color (Hamm et al., 2015) or simply fail to report findings about youth of color in their review (Kowalski et al., 2014). Hamm et al. (2015) explored the frequency and impact of cyberbullying on youth in 36 studies that focused on health-related effects of cyberbullying. Authors reported that only seven studies explored the relationship of ethnicity and cyberbullying behavior, with only two studies examining ethnic populations (Hispanic, African American, Hawaiian, Filipino, and Samoan) in the United States.

In their review of 81 cyberbullying studies, Selkie, Fales and Moreno (2015) intentionally excluded research that focused solely on "special populations", such as students with disabilities or who identified as lesbian, gay, bisexual, transgender queer/questioning (LGBTQ). Although the authors did not specifically mention race or ethnicity as a special population, they also did not report findings about members of these communities, either as specific populations or sample subgroups within the general samples. Chisohlm (2014) reviewed the status of cyberbullying research and pre- vention strategies, once again focusing on findings about gender difference, platform differences and called for additional research on age, gender and class diversity among bullying and cyberbullying participants but fell short of seeking racial diversity. Finally, in one of the most extensive reviews of cyberbullying research to date, Kowalski et al. (2014) reviewed and conducted a meta-analysis of 131 studies about cyberbullying and youth. Among other things, their review reported on the prevalence and antecedents of cyberbullying, including demographic factors like gender and age; however, the authors neglected to review or report the role of race/ethnicity in cyberbullying.

\subsection{Youth of Color and the Digital Divide}

As noted earlier, the use (and abuse) of technology is the defining characteristic of cyberbullying, therefore an exploration of racial and ethnic differences in cyberbullying should begin with an exploration of these differences in the everyday digital lives for youth of color. Youth today are regularly immersed in digital technologies, with $92 \%$ of teens going online daily and $76 \%$ using social media to connect with friends and peers. Teens are also heavy texters, sending and receiving an average of 30 texts per day on a variety of digital platforms (Lenhart et al., 2015). The time that youths spend online can best be described as pleasant, with nearly $70 \%$ of social network using teens saying that most of their peers are kind to each other online (Lenhart et al., 2011). This finding is consistent with reported rates of cyberbullying ("unkindness") of $20 \%$.

But there are some racial differences in youths' online practices and experiences. According to data from the PEW Research Center, 92\% of youth go online daily, with $24 \%$ of youth reporting that they go online "almost constantly". In comparison, $34 \%$ of black teens and $32 \%$ of Hispanic teens are online almost constantly; only $19 \%$ of white teens report this much usage (Lenhart et al., 2015; Tynes \& Mitchell, 2014). And there are differences in where youth spend their time online, too. Seventy-one percent of all youth report using Facebook regularly, but black teens report using Instagram in significantly higher percentages (64\%) than their white peers (50\%). Thirty-three percent of all youth use Twitter, but $45 \%$ of black teens prefer this site compared to $31 \%$ of Hispanic youth and $30 \%$ of white youth (Lenhart et al., 2015). It should be noted that despite sharing the "social media" label, Twitter, Instagram and Facebook have distinctly different discursive cultures, with Facebook being more about sharing, exchanging, and interacting with "friends" in a predominantly two-way model of communication; Twitter and Instagram are more about posting brief statements and being read by "followers" in an essentially one-way model.

The most marked difference, however, is in tech- 
nology ownership with $85 \%$ of black youth owning smartphones, compared to $71 \%$ of white and Hispanic youth (Lenhart et al., 2015); however, black teens are significantly less likely (40\%) than their white and Hispanic peers (61\% and $62 \%$, respectively) to use their smartphones to communicate with friends on a daily basis.

Aside from these general usage patterns, very few researchers have explored the role or significance of race and ethnicity in cyberbullying experiences (Hinduja \& Patchin, 2010; Juvonen et al., 2003; Low \& Espalage, 2013; Wang, lannotti, Luk, \& Nansel, 2010; Wang et al., 2009). This current review, therefore, will begin with the studies of online and offline bullying and youth of color that we were able to find and then we move on to research about mental health outcomes.

\section{Methods}

Articles were obtained from searches on Psychlnfo, PubMed, and CommAbstracts using search terms: cyberbullying, race, ethnicity, African American, black, Asian, and Hispanic. This returned a total of 165 articles. Articles were included for analysis if the sample consisted of youth with ages from 10-18 and if race or ethnicity was identified as a variable (or the sample consisted of at least 50\% non-white youths). Only English-language studies were included; duplicate studies, critical essays, literature reviews, book reviews, and opinion pieces were excluded. These constraints resulted in a total of 15 studies for this review. Given the predominance of studies that analyzed bullying in conjunction with cyberbullying $(k=14)$, findings for both traditional and cyberbullying are reported. In a majority of these studies $(k=12)$, participants completed online surveys administered in classroom settings. Participants were primarily middle school students with sample sizes that ranged from 370-671 for Asian, 5712227 for Hispanic, and 1350-2760 for black youth.

\section{Results}

\subsection{Bullying and Youth of Color}

Youth of color share some commonalities with each other in their cyber-bullying and offline bullying experiences, but there are also some notable differences, as shown in Table 1. Youth of color report lower levels of cyber-victimization than their white peers; indeed, black and Hispanic youth are more likely to be cyber-bullies and offline bullies than victims of bullying. Black and Hispanic teens report levels of cyberbullying victimization similar to the national average (from $16 \%$ to $30 \%$ ); however, black and Hispanic rates are at the lower range of national averages, and they report levels of offline bullying perpetration similar to white peers (Carter \& Wilson, 2015; Low \& Espelage, 2013; Wang et al., 2009).
Offline (or traditional) bullying includes physical acts of aggression, verbal aggression and relational attacks designed to disrupt victims' interpersonal relationships (Willard, 2007). Hispanic and black adolescents were found to be more likely to be physical bullies than their white, black and Asian peers (Nansel, et al., 2001; Wang, lannotti, \& Luk, 2012; Wang et al., 2009). Although black youth were significantly less bullied than any of their peers, they do experience racial bullying like Asian and Hispanic youth, an area often overlooked in cyber-bullying research (Arat, 2015; Fisher et al., 2015; Goldweber, Waasdorp, \& Bradshaw, 2013; Nansel et al., 2001; Stone \& Carlisle, 2015; Williams \& Peguero, 2013). When looking at cooccurrence of traditional, non-physical bullying and cyberbullying, there were no differences among Hispanic, black, and white teens. Victims of traditional bullying were also often victims of cyberbullying (Nansel, et al., 2001; Wang et al., 2009; Wang et al., 2010).

There are gender differences in cyber-victimization experiences among male and female youth of color, similar to their white peers. Black and Hispanic males were less likely to report cyberbullying victimization than their female counterparts (Merrill \& Hanson, 2016; Romero, Wiggs, Valencia, \& Bauman, 2013; Wang et al., 2009; Wang et al., 2010; Wang et al., 2011; Wang et al., 2012). Black girls experience more online sexual harassment and solicitation than their black and Hispanic male peers (Tynes \& Mitchell, 2014).

Table 1. Rates of offline bullying and cyberbullying participation for youth of color.

\begin{tabular}{lllll}
\hline $\begin{array}{l}\text { Race/ } \\
\text { ethnicity }\end{array}$ & $\begin{array}{l}\text { Offline } \\
\text { bullying }\end{array}$ & $\begin{array}{l}\text { Cyber } \\
\text { Bullying }\end{array}$ & $\begin{array}{l}\text { Offline } \\
\text { victimi- } \\
\text { zation }\end{array}$ & $\begin{array}{l}\text { Cyber } \\
\text { victimi- } \\
\text { zation }\end{array}$ \\
\hline & $\%$ & $\%$ & $\%$ & $\%$ \\
Black & $18-46$ & $7-11$ & $7-30$ & $4-17$ \\
Hispanic & $18-37$ & $16-18$ & $10-17$ & $6-13$ \\
Asian & - & - & $20-24$ & $15-57^{\mathrm{b}}$ \\
White & $11-23$ & $4-42^{\mathrm{b}}$ & $10-22$ & $18-30$ \\
\hline
\end{tabular}

Note: These ranges reflect the best available data we have, rounded up to the nearest whole number; (-) denotes absence of available data from studies reviewed for this article. ${ }^{a}=$ Offline bullying ranges include physical, verbal, and relational bullying; ${ }^{b}=$ The upper range appeared in only one study. The upper range of cybervictimization for Asian youth is $18 \%$ when the additional study is omitted and the upper range for cyber-bullying for white youth is $35 \%$ without the additional study.

In summary, Hispanic and black youth are more likely than white and Asian youth to engage in offline, rather than online, bullying perpetration. The inverse is true regarding victimization, with black and Hispanic youth experiencing less online and offline victimization than 
white and Asian youth. The only similarity was found in the victimization experienced by black and Hispanic girls and white females-all teen girls experienced more online and offline victimization than their male counterparts.

\subsection{Mental Health Outcomes}

As shown in Table 2, the data about mental health effects for youth of color are spotty; several studies failed to even report mental health outcomes for youth of color in their samples (Merrill \& Hanson, 2016; Wang et al., 2010; Wang et al., 2011). Luk, Wang and Simons-Morton (2012) found no racial difference in cyber- or offline victimization and association with substance use or depression. Hispanic youth appear to be particularly vulnerable to depressive effects, although Asian youths' adverse mental health outcomes were associated with lower levels of cyberbullying than other youth of color (Arat, 2015; Goebert, Else, Matsu, Chung-do, \& Chang, 2011). Suicidal ideation is also significantly related to race among youth involved in cyberbullying, particularly for Hispanic females (Hinduja \& Patchin, 2010; Romero et al., 2013). In sum, based on these findings, there do not appear to be large racial-ethnic differences in suicidal ideation or attempts for youth exposed to cyberbullying.

Table 2. Types of mental health outcomes for youth of color who are involved in offline and cyberbullying as bullies and/or victims.

\begin{tabular}{lllll}
\hline $\begin{array}{l}\text { Race/ } \\
\text { ethnicity }\end{array}$ & $\begin{array}{l}\text { Depressive } \\
\text { symptoms }\end{array}$ & $\begin{array}{l}\text { Suicidal } \\
\text { ideation }\end{array}$ & $\begin{array}{l}\text { Suicide } \\
\text { attempt }\end{array}$ & Other \\
\hline \multirow{4}{*}{ Black } & $\%$ & $\%$ & $\%$ & $\%$ \\
Hispanic & - & $8-25$ & $8-16$ & $25-27$ \\
Asian & $8-27$ & $14-23$ & $10-12$ & $32-34$ \\
White & - & $19-22$ & - & - \\
\hline
\end{tabular}

Note: These ranges reflect the best available data we have, rounded up to the nearest whole number. (-) denotes absence of available data from studies reviewed for this article.

\section{Discussion}

From technology ownership to social media engagement, youth of color interact differently with technology and with each other compared to their white peers (Lenhart et al., 2011; Lenhart et al., 2015; Tynes \& Mitchell, 2014; Wout, Murphy \& Steele, 2010). As noted earlier, $85 \%$ of black youth own smartphones but are significantly less likely $(40 \%)$ than their white and Hispanic peers ( $61 \%$ and $62 \%$, respectively) to use their smartphones to communicate with friends on a daily basis (Lenhart et al., 2015). This difference suggests, at the least, that these communities may also experience cyberbullying differently. In particular, although these communities appear to experience cyber-victimization at lower rates than white youth, they report levels of suicidal ideation and attempts associated with such victimization at about the same rates as white youth.

On one hand, there is evidence to suggest that there is little significant difference between youth of color and their white peers in terms of cyberbullying perpetration or in terms of gender differences in victimization (Low \& Espelage, 2013; Romero et al., 2013; Tynes \& Mitchell, 2014). However, research also indicates that black and Hispanic youth are more likely to bully others (offline) than to cyberbully others and are less likely to be victims (Merrill \& Hanson, 2016; Romero et al., 2013; Wang et al., 2009; Wang et al., 2010; Wang et al., 2011; Wang et al., 2012). These findings are consistent with previous research detailing teacher perceptions of black youth aggression and bullying behavior in school (Albdour \& Krouse, 2014; Tynes \& Mitchell, 2014).

The lower rates of cyberbullying for black youth may be related to their differing levels of technology ownership. Black households are less likely to own computers and have Internet access than their white peers, making it more difficult to cyberbully anyone. Black youth also report preferring Twitter (Lenhart et al., 2015), which means more anonymous audience members (and, therefore, fewer readily identifiable victims). However, black youth are more likely to own smartphones, but not necessarily use them for connecting with friends. One reason may be that face-toface interactions may be valued over using technology to interact with friends in the black community, a community that is already characterized by cultural communication differences from other racial and ethnic groups (Neu, 2008; Saloy, 2013; Williams \& Peguero, 2013). Finally, given the lower rates of computer and Internet use in home, it is possible that black youth are financially responsible for their smartphones. If individual phone plans set usage limits, black youth may be particularly diligent (or frugal) with their phones which makes using smartphones to keep in touch with their friends (or to cyberbully anyone) a costly proposition.

\section{Limitations}

There are several limitations to this study. First, the small number of studies reviewed $(k=15)$ makes it difficult to draw firm conclusions. This may have been caused by the limitations imposed by search terms; if "Cyberbully" wasn't in the article keyword, then the study may have been missed. Also gender differences among youth of color weren't clearly discernable in this literature, with one or two exceptions (Messias, Kindrick, \& Castro, 2014; Romero et al., 2013). Second, 
the findings were difficult to synthesize because researchers reported their findings in a variety of formats, despite the majority of the studies utilizing a similar instrument (survey). Finally, approximately onethird of the research reviewed here was conducted by members of the same research team, using one sample of participants (Wang et al, 2009; Wang et al, 2010; Wang et al, 2011; Wang et al., 2012). Future research should attempt to expand the diversity of the samples used to increase the potential for significant findings about youth of color and, more importantly, researchers should consistently report all findings regarding racial and ethnic minorities in their studies.

\section{Conclusions}

Cyberbullying continues to be a serious issue for youth of all races, especially given the adverse mental health effects suffered by some victims. This review of cyberbullying research shows that although whites are bullied online more than non-whites, the rates of suicidal ideation are comparable. This is particularly interesting given the differences between youth of color and their white peers in terms of technology ownership, social media preferences, and socioeconomic backgrounds. This would suggest that the digital divide may shield youth of color from cyberbullying somewhat; however, the divide can't shield them from cyberbullying effects.

\section{Acknowledgements}

This material is based upon work supported by the National Science Foundation under Grant Nos. 0916152 and 1421896. Any opinions, findings, and conclusions or recommendations expressed in this material are those of the author(s) and do not necessarily reflect the views of the National Science Foundation.

\section{Conflict of interests}

The authors declare no conflicts of interests.

\section{References}

Albdour, M. \& Krouse, H. J. (2014). Bullying and victimization among African American adolescents: A literature review. Journal of Child and Adolescent Psychiatric Nursing, 27, 68-82.

Arat, G. (2015). Emerging protective and risk factors of mental health in Asian American students: Findings from the 2013 youth risk behavior survey. Vulnerable Children and Youth Studies, 10(3), 192-205.

Barboza, G. E. (2015). The association between school exclusion, delinquency and subtypes of cyber and F2F victimizations: Identifying and predicting risk profiles and subtypes using latent class analysis. Child abuse \& Neglect, 39, 109-122.
Bhatta, M. P., Shakya, S., \& Jefferis, E. (2014). Association of being bullied in school with suicide ideation and planning among rural middle school adolescents. Journal of School Health, 84(11), 731-738.

Campfield, D. (2006). Cyber bullying and victimization: Psychosocial characteristics of bullies, victims, and bully/victims (Unpublished Doctoral Dissertation). University of Montana, Missoula, MT.

Carter, J. M. \& Wilson, F .L. (2015). Cyberbullying: A $21^{\text {st }}$ century health care phenomenon. Pediatric Nursing, 41(3), 115-125.

Cassidy, W., Faucher, C., \& Jackson, M. (2013). Cyberbullying among youth: A comprehensive review of current international research and its implications and application to policy and practice. School Psychology International, 34, 575-612.

Chisholm, J. F. (2014). Review of the status of cyberbullying and cyberbullying prevention. Journal of Information Systems Education, 25(1), 77-87.

Davison, C. B., \& Stein, C. H. (2014). The dangers of cyberbullying. North American Journal of Psychology, 16(3). Retrieved from http://najp.8m.com

Dempsey, A. G., Sulkowski, M. L., Nichols, R., \& Storch, E. A. (2009). Differences between peer victimization in cyber and physical settings and associated psychosocial adjustment in early adolescence. Psychology in the Schools, 46, 962-972.

Fisher, S., Middleton, K., Ricks, E., Malone, C., Briggs, C., \& Barnes, J. (2015). Not just black and white: Peer victimization and the intersectionality of school diversity and race. Journal of Youth Adolescence, 44, 1241-1250.

Goebert, D., Else, I., Matsu, C., Chung-Do, J. \& Chang, J. Y. (2011). The impact of cyberbullying on substance use and mental health in a multiethnic sample. Maternal Child Health Journal, 15, 1282-1286. doi:10. 1007/s10995-010-0672-x

Goldweber, A., Waasdorp, T. E., \& Bradshaw, C. P. (2013). Examining associations between race, urbanicity, and patterns of bullying involvement. Journal of Youth Adolescence, 42, 206-219. doi:10.1007/ s10964-012-9843-y

Hamm, M. P., Newton, A. S., Chisholm, A., Shulhan, J., Milne, A., Sundar, P., . . . Harling, L. (2015). Prevalence and effect of cyberbullying on children and young people. JAMA Pediatrics, 169(8), 770-777. doi:10.1001/jamapediatrics.2015.0944

Hinduja, S., \& Patchin, J. W. (2010). Bullying, cyberbullying, and suicide. Archives of Suicide Research, 14, 206-221. doi:10.1080/13811118.2010.494133

Hodges, E. V., \& Perry, D. G. (1999). Personal and interpersonal antecedents and consequences of victimization by peers. Journal of Personality and Social Psychology, 76, 677-685.

Holfeld, B., \& Leadbeater, B. J. (2015). The nature and frequency of cyber bullying behaviors and victimization experiences in young Canadian children. Cana- 
dian Journal of School Psychology, 30, 116-135.

Horowitz, M., \& Bollinger, D. M. (2014). Cyberbullying in social media within educational institutions. New York: Roman \& Littlefield.

Houbre, B., Tarquinio, C., Thuillier, I., \& Hergott, E. (2006). Bullying among students and its consequences on health. European Journal of Psychology of Education, 21, 183-208.

Juvonen, J., Graham, S., \& Schuster, M.A. (2003). Bullying among young adolescents: The strong, the weak, and the troubled. Pediatrics, 112, 1231-1237.

Kann, L., Kinchen, S., Shanklin, S. L., Flint, K.H., Hawkins, J., Harris, W. A., . . Zaza, S. (2014). Youth risk behavior surveillance: United States, 2013. Morbidity and Mortality Weekly Report, 63(4). Retrieved from http://www.cdc.gov/mmwr

Klomek, A. B., Marracco, F., Kleinman, M., Schonfeld, I. S., \& Gould, M. S. (2007). Bullying, depression, and suicidality in adolescents. Journal of the American Academy of Child and Adolescent Psychiatry, 46, 4049.

Kowalski, R. M., Giumetti, G. W., Schroeder, A. N., \& Lattanner, M. R. (2014). Bullying in the digital age: $A$ critical review and meta-analysis of cyberbullying research among youth. Psychological Bulletin, 140(4), 1073-1137. doi:10.1037/a0035618

Kubiszewski, V., Fontaine, R., Potard, C., \& Auzoult, L. (2015). Does cyberbullying overlap with school bullying when taking modality of involvement into account? Computers in Human Behavior, 43, 49-57.

Lenhart, A., Madden, M., Smith, A., Purcell, K., Zickuhr, K., \& Rainie, L. (2011). Teens, kindness and cruelty on social network sites. Pew Research Center's Internet and American Life Project. Retrieved from http://www.pewinternet.org/2011/11/09/teenskindness-and-cruelty-on-social-network-sites/

Lenhart, A., Smith, A., Anderson, M., Duggan, M., \& Perrin, A. (2015). Teens, technology, and friendships. Pew Research Center. Retrieved from http://www.pe winternet.org/files/2015/08/Teens-and-FriendshipsFINAL2.pdf

Li, Q. (2007). Bullying in the new playground: Research into cyberbullying and cyber victimization. Australasian Journal of Educational Technology, 23, 435-454.

Low, S., \& Espelage, D. (2013). Differentiating cyber bullying perpetration from non-physical buying: Commonalities across race, individual, and family predictors. Psychology of Violence, 3(1), 39-52. doi:10.10 37/a0030308.

Luk, J. W., Wang, J., \& Simons-Morton, B. G. (2012). The co-occurrence of substance use and bullying behaviors among U.S. adolescents: Understanding demographic characteristics and social influences. Journal of Adolescence, 35(5), 1351-1360. doi:10.1016/j.adol escence.2012.05.003

Maher, D. (2008). Cyberbullying: An ethnographic case study of one Australian upper primary school class.
Youth Studies Australia, 27(4), 50-58.

Menesini, E., Nocentini, A., Palladino, B. E., Frise'n, A., Berne, S., Ortega, R., \& Smith, P. K. (2012). Cyberbullying definition among adolescents: A comparison across six European countries. Cyberpsychology, Behavior, and Social Networking, 15, 455-463.

Merrill, R. M., \& Hanson, C. L. (2016). Risk and protective factors associated with being bullied on school property compared with cyberbullied. BMC Public Health, 16(145). doi:10.1186/s12889-016-2833-3

Messias, E., Kindrick, K., \& Castro, J. (2014). School bullying, cyberbullying, or both: Correlates of teen suicidality in the 2011 CDC youth risk behavior survey. Comprehensive Psychiatry, 55(5), 1063-1068. doi:10. 1016/j.comppsych.2014.02.005.

Mueller, A. S., James, W., Abrutyn, S., \& Levin, M. L. (2015). Suicide ideation and bullying among US adolescents: Examining the intersections of sexual orientation, gender, and race/ethnicity. American Journal of Public Health, 105, 980-985.

Nansel, T. R., Overpeck, M., Pilla, R. S., Ruan, W. J., Simons-Morton, B., \& Scheidt, P. C. (2001). Bullying behaviors among US youth: Prevalence and association with psychosocial adjustment. Journal of the American Medical Association, 285, 2094-2100.

Neu, J. (2008). Sticks and stones: The philosophy of insults. New York: Oxford University Press.

Olweus, D. (1993). Bullying at school: What we know and what we can do (1st ed.). Oxford: WileyBlackwell.

Price, M., Chin, M. A., Higa-McMillan, C., Kim, S., \& Frueh, B. C. (2013). Prevalence and internalizing problems of ethnoracially diverse victims of traditional and cyber bullying. School Mental Health, 5, 183-191. doi:10.1007/s12310-013-9104-6

Raskauskas, J., \& Stoltz, A.D. (2007). Involvement in traditional and electronic bullying among adolescents. Developmental Psychology, 43, 564-575.

Romero, A. J., Wiggs, C. B., Valencia, C., \& Bauman, S. (2013). Latina teen suicide and bullying. Hispanic Journal of Behavioral Sciences, 35(2), 159-173. doi:10.1177/0739986312474237

Saloy, M. L. (2013). African American oral traditions in Louisiana. Folklife in Louisiana. Retrieved from http://www.louisianafolklife.org/LT/Articles_Essays/ creole_art_african_am_oral.html

Sampasa-Kanyinga, H., Roumeliotis, P., \& Xu, H. (2014). Associations between cyberbullying and school bullying victimization and suicidal ideation, plans and attempts among Canadian schoolchildren. PLOS ONE, 9, e102145.

Schneider, S. K., O’Donnell, L., Stueve, A., \& Coulter, R. W. (2012). Cyberbullying, school bullying, and psychological distress: A regional census of high school students. American Journal of Public Health, 102, 171-177.

Selkie, E. M., Fales, J. L., \& Moreno, M. A. (2015). Cyber- 
bullying prevalence among US middle and high school-aged adolescents: A systematic review and quality assessment. Journal of Adolescent Health, 58(2), 125-133. doi:10.1016/j.jadohealth.2015.09.026

Shojaei, T., Wazana, A., Pitrou, I., Gilbert, F., \& Kovess, V. (2009). Self-reported peer victimization and child mental health: Results of a cross-sectional survey among French primary school children. Journal of Developmental and Behavioral Pediatrics, 30, 300309.

Smith, P. K., \& Monks, C. P. (2008). Concepts of bullying: Developmental and cultural aspects. International Journal of Adolescent Medicine and Health, 20, 101112.

Stone, A. L. \& Carlisle, S. K. (2015). Racial bullying and adolescent substance use: An examination of schoolattending young adolescents in the United States. Journal of Ethnicity in Substance Abuse, 15(1), 1-20. doi:10.1080/15332640.2015.1095666

Storch, E. A., Masia-Warner, C., Crisp, H., \& Klein, R. G. (2005). Peer victimization and social anxiety in adolescence: A prospective study. Aggressive Behavior, 31, 437-452.

Tynes, B. M. \& Mitchell, K. J. (2014). Black youth beyond the digital divide: Age and gender differences in Internet use, communication patterns, and victimization experiences. Journal of Black Psychology, 40(3), 291-307. doi:10.1177/0095798413487555

Wang, J., lannotti, R. J., \& Luk, J. W. (2012). Patterns of adolescent bullying behaviors: Physical, verbal, exclusion, rumor, and cyber. Journal of School Psychol- ogy, 50, 521-534. doi:10.1016/j.jsp.2012.03.004

Wang, J., lannotti, R. J., Luk, J. W., \& Nansel, T. R. (2010). Co-occurrence of victimization from five subtypes of bullying: Physical, verbal, social exclusion, spreading rumors, and cyber. Journal of Pediatric Psychology, 35(10), 1103-1112. doi:10.1093/jpepsy/jsq048

Wang, J., lannotti, R. J., \& Nansel, T. R. (2009). School bullying among US adolescents: Physical, verbal, relational, and cyber. Journal of Adolescent Health, 45, 368-375. doi:10.1016/j.jadohealth.2009.03.021

Wang, J., Nansel, T. R., \& lannotti, R. J. (2011). Cyber bullying and traditional bullying: Differential association with depression. Journal of Adolescent Health, 48, 415-417. doi:10.1016/j.jadohealth.2010.07.012

Willard, N. E. (2007). Cyberbullying and cyberthreats: Responding to the challenge of online social aggression, threats, and distress. Champaign, IL: Research Press.

Williams, L. M., \& Peguero, A. A. (2013). The impact of school bullying on racial/ethnic achievement. Race and Social Problems, 5, 296-308.

Wolak, J., Mitchell, K. J., \& Finkelhor, D. (2007). Does online harassment constitute bullying? An exploration of online harassment by known peers and online-only contacts. Journal of Adolescent Health, 4. doi:10.1016/j.jadohealth.2007.08.019

Wout, D. A., Murphy, M. C., \& Steele, C. M. (2010). When your friends matter: The effect of white students' racial friendship networks on metaperceptions and perceived identity contingencies. Journal of Experimental Social Psychology, 46, 10351041. doi:10.1016/j.jesp.2010.06.003

\section{About the Authors}

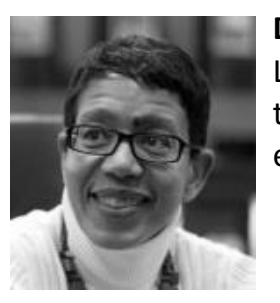

\section{Dr. Lynne Edwards}

Lynne Edwards is a Professor of Media and Communication Studies at Ursinus College and is the author of several publications about youth and cyber-crime. Dr. Edwards has received over $\$ 900,000$ in external funding to support her research and to pursue commercialization opportunities.

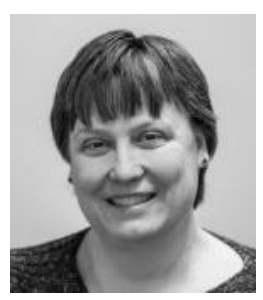

\section{Dr. April Edwards Kontostathis}

April Edwards Kontostathis is Professor of Mathematics and Computer Science and Interim Dean of the College at Ursinus College. Her primary research interest is textual data mining, with an emphasis on the detection and prevention of cyberbullying and Internet sexual predation. Dr. Kontostathis has published over 40 articles and has received over $\$ 1.1$ million in extramural funding for research, undergraduate student support, and research commercialization.

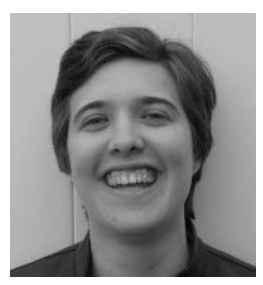

\section{Christina Fisher}

Christina Fisher is a cum laude graduate of the Department of Psychology at Ursinus College. 